\title{
Exposición compleja de placa craneal
}

\author{
Complex exposure of cranial plate
}

\author{
Autora: Romina C. Triglia1. Coautor: Mario Menon²
}

\section{RESUMEN}

Es recomendable que los pacientes con antecedentes de trauma craneal mode rado o grave, con pérdida de fragmentos de calota, que deben reparar con posterior craneoplastia, la realicen luego de 3 a 6 meses, reduciendo el riesgo de infección y de hipertensión endocraneana. Los materiales a utilizar son diversos; y para evitar la reapertura es fundamental un cierre sin tensión, en dos planos y sin tejido desvitalizado. Las infecciones son raras; son más frecuentes cuando la craneopatía se realizó dentro del 1er año del trauma. Otra complicación es la úlcera crónica, de manejo muy complejo.

Material y métodos. Paciente de 58 años, sufrió un traumatismo encefalocraneano con pérdida de conocimiento en el año 2011, por accidente de tránsito; craneoplastia realizada a 8 meses del trauma, posterior ulceración sobre líneas de incisión en dos oportunidades, reparado en ambas con colgajos locales, conservando la placa craneal. La paciente consultó presentando nueva ulceración parietal izquierda y adelgazamiento del cuero cabelludo y translucencia del material frontoparietal izquierdos; sin infección local; y múltiples cicatrices remanentes. Se retiró la placa craneal, y a dos años se realizó expansión con insuflados lentos controlados con la signosintomatología que presentaba la paciente. Al 3er mes se recolocó nueva placa de titanio y cobertura con colgajos del cuero cabelludo. Discusión. La expansión tisular del cuero cabelludo es un método simple, con baja frecuencia de complicaciones si la técnica es delicada y atendemos la signosintomatología del paciente. Conclusión. El trabajo conjunto multidisciplinario, es la piedra angular para obtener resultados óptimos en la reconstrucción de lesiones complejas.

Palabras claves: trauma craneal, placa de titanio expuesta, expansión de cuero cabelludo.

\begin{abstract}
Patients with a history of moderate or severe skull trauma, with loss of shell fragments, which must be repaired with subsequent cranioplasty, it is recommended to perform it after 3 to 6 months, reducing the risk of infection and endocranial hypertension. The materials to use are diverse; and to avoid reopening, a tension-free closure is essential, in two planes and without devitalized tissue. Infections are rare, being more frequent when the craniopathy took place within 1 year of the trauma. Another complication is the chronic ulcer, very complex to handle.

Material and methods. Fifty eight year-old patient, suffered a traumatic brain injury with loss of consciousness in 2011, due to a traffic accident; craneoplasty performed 8 months after trauma, subsequent ulceration on incision lines on two occasions, both repaired with local flaps, preserving the cranial plate. The patient consulted presenting a new left parietal ulceration, and thinning of the scalp and translucency of the left fronto-parietal material; no local infection; and multiple remaining scars. The cranial plate was removed, and two years later, expansion was performed with slow insufflants controlled with the patient's symptom sign. At the 3rd month, a new titanium plate was replaced and covered with flaps of the scalp.

Discussion. Tissue expansion of the scalp is a simple method, with little frequency of complications if the technique is delicate, and we attend to the patient's sign-symptomatology.

Conclusion. Multidisciplinary joint work is the cornerstone for obtaining optimal results in the reconstruction of complex injuries.
\end{abstract}

Keywords: skull trauma, exposed titanium plate, tissue expansion of the scalp.

REVISTA ARGENTINA DE CIRUGÍA PLÁSTICA 2020;26(2):92-98. HTTPS://DOI.ORG/10.32825/RACP/202002/0092-0098

\section{INTRODUCCIÓN}

En un estudio realizado en la ciudad de Buenos Aires se reportó que la incidencia de traumatismo encefalocraneano (TEC) es de 322 pacientes cada 100,000 habitantes. La gran mayoría de estos (93\%) corresponden a casos leves, mientras que el $7 \%$ restante, a casos moderados y graves. Dicha forma de trauma es más frecuente en hombres que en mujeres, y las edades con mayor afectación son de 15 a 30 años en varones, y de 38 a 49 años en mujeres.

Las causas más comunes de este tipo de traumatismos son los accidentes de tránsito, y también las agresiones físicas. Cuando un paciente presenta un trauma de cráneo

1. Especialista en Cirugía Plástica y Reparadora. Miembro Titular SACPER.

2. Especialista en Neurocirugía.

Sanatorio CEMEDA, ciudad de Olavarría, Pcia. Buenos Aires, Rep. Argentina

$\triangle$ Correspondencia: Romina C.Triglia. rominatriglia@gmail.com

Los autores no declaran conflictos de intereses.

Recibido: 04/04/2020 / Aceptado: 05/05/2020 moderado o grave, en el cual se lo somete a algún tipo de intervención quirúrgica en la que se desechan fragmentos óseos de calota, con el objetivo de realizar una craneotomía descompresiva luego del tiempo que se estime necesario, esta deberá ser reconstruida mediante una craneoplastia.

Las craneoplastias están indicadas siempre que un paciente pierda sustancia ósea craneal, ya sea secundaria a un trauma, como dijimos antes, posterior a la resección de un tumor óseo en la calota, o pacientes con algún tipo de infección, etc. El objetivo es proteger el cerebro subyacente, restaurar la estética y evitar la atrofia cerebral secundaria que produce convulsiones y otras alteraciones.

En el caso de pacientes con antecedentes de traumatismo craneal, la craneoplastia debe realizarse de 3 a 6 meses posteriores al mismo, debido al elevado riesgo de infección que presentan y para evitar la hipertensión endocraneana que genera el edema postrauma.

Los materiales que se utilizan con mayor frecuencia en las craneoplastias son:

Hueso autólogo. Presenta mayor índice de resorción ósea como principal complicación, y también existen posibilidades de infección y fracturas múltiples. 


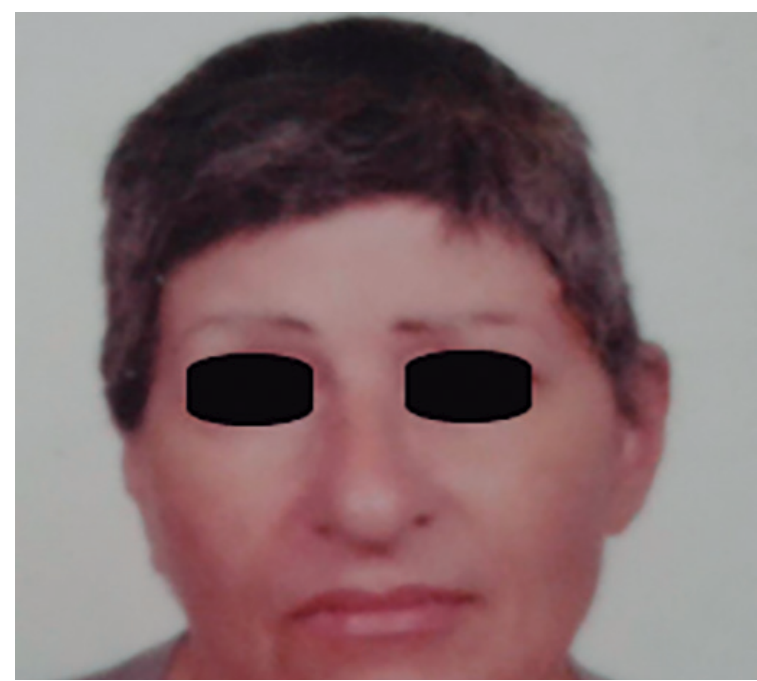

Figura 1. Paciente en el año 2013 (foto facilitada por la paciente, previa a su primera consulta).

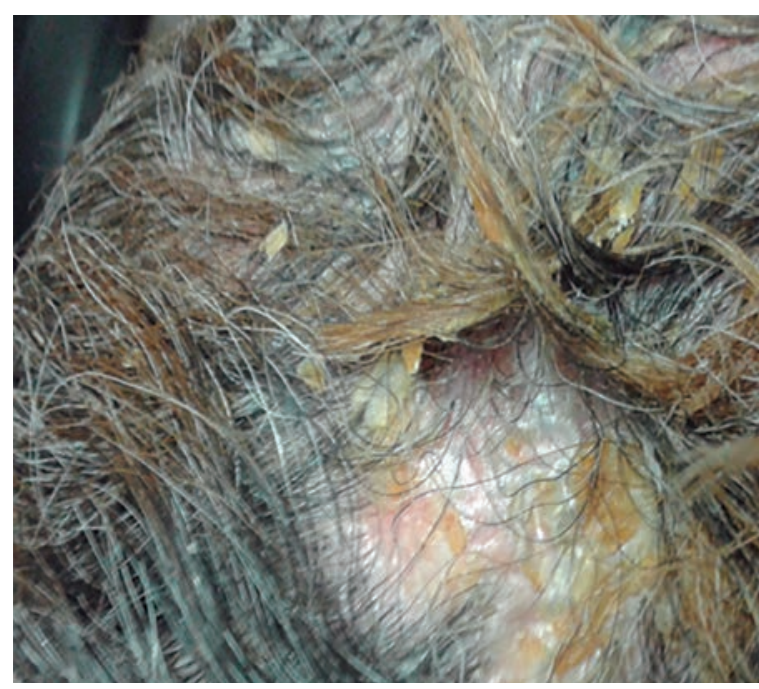

Figura 3. Cuero cabelludo adelgazado.

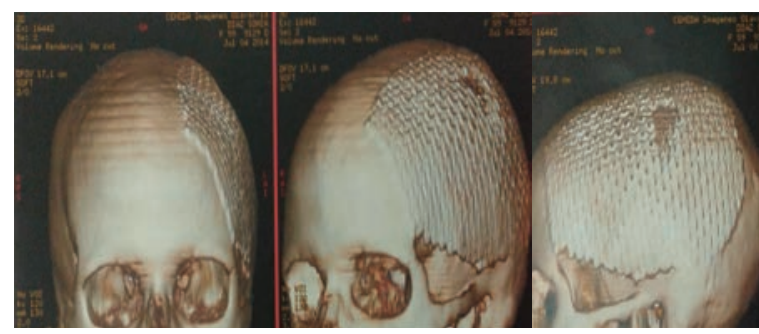

Figura 5. La tomografía computarizada con reconstrucción 3D evidencia el tamaño de la placa craneal y el tamaño de la craneotomía.

Metilmetacrilato. Es otro de los elementos utilizados, que presenta poca adherencia, y puede causar reacción tisular con colecciones subcutáneas. No es el elemento de elección ante grandes defectos óseos craneales, y además es el más susceptible de infecciones.

Metales, como el titanio. Este último soporta grandes cargas bacterianas, es más radiolúcido y más liviano que otros, es un elemento fuerte, biocompatible y no

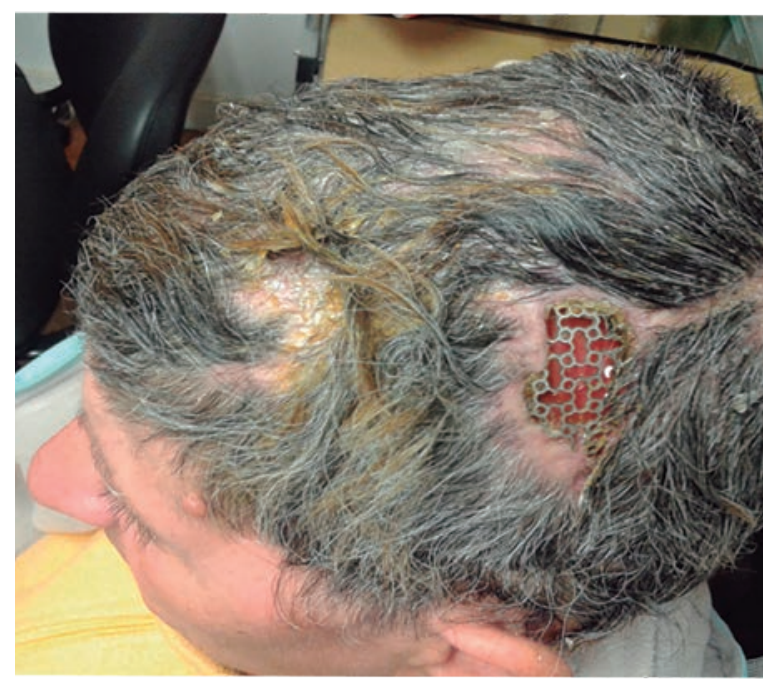

Figura 2. Exposición de placa craneal.

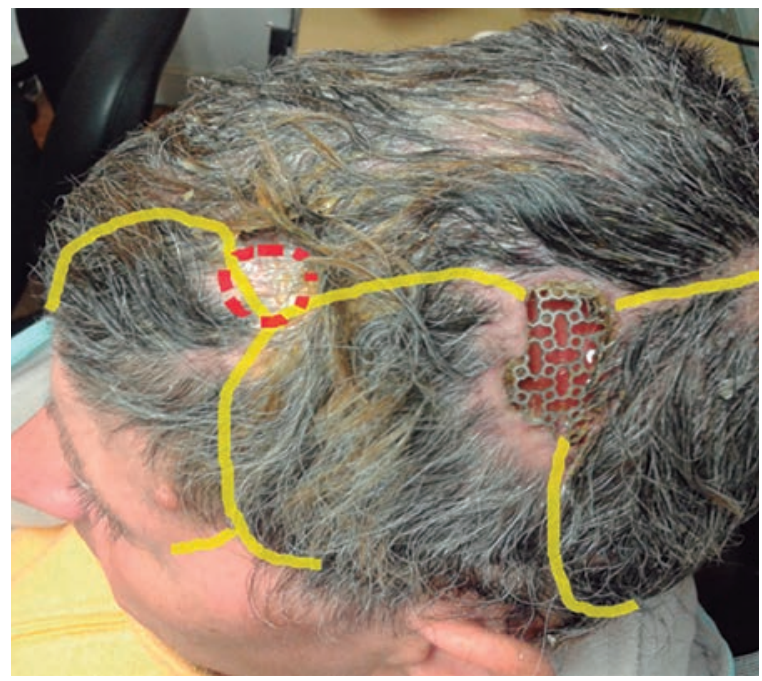

Figura 4. Las líneas amarillas representan cicatrices de cirugias previas. Las líneas a trazos rojas representan zonas de adelgazamiento y translucencia del cuero cabelludo.

genera hipersensibilidad. La malla de titanio presenta muy buena integración al tejido adyacente.

Polietileno poroso. Es un material biocompatible, maleable, fuerte, no tóxico ni carcinogénico, es más resistente a las infecciones en relación con los anteriores, suele ser bien tolerado, no antigénico, es esterilizable y radiolúcido. Su porosidad facilita la revascularización y el crecimiento tisular circundante reforzando el implante. Lo más importante, al realizar una craneoplastia, es que debemos lograr una impecable cobertura con tejidos blandos y para esto debemos evitar el cierre a tensión de heridas, evitar la presencia de tejido blando desvitalizado y utilizar dos planos de sutura en el cierre. Si por algún motivo esto no se logra, existe una probabilidad muy alta de que las heridas se abran y el material de osteosíntesis se exponga.

Existe la posibilidad de que las craneoplastias sufran algunas complicaciones como las que detallaremos: 


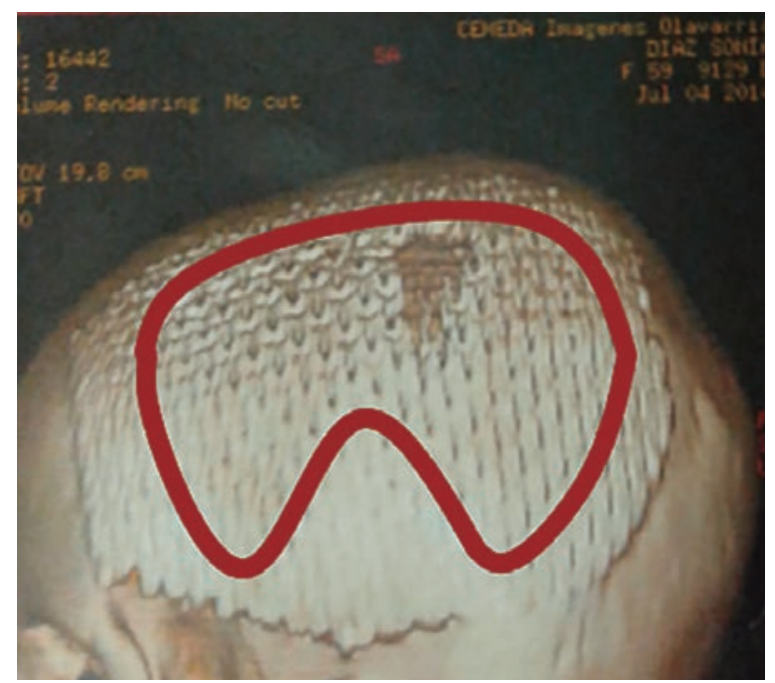

Figura 6. La línea roja remarca el reborde de la craneotomía.

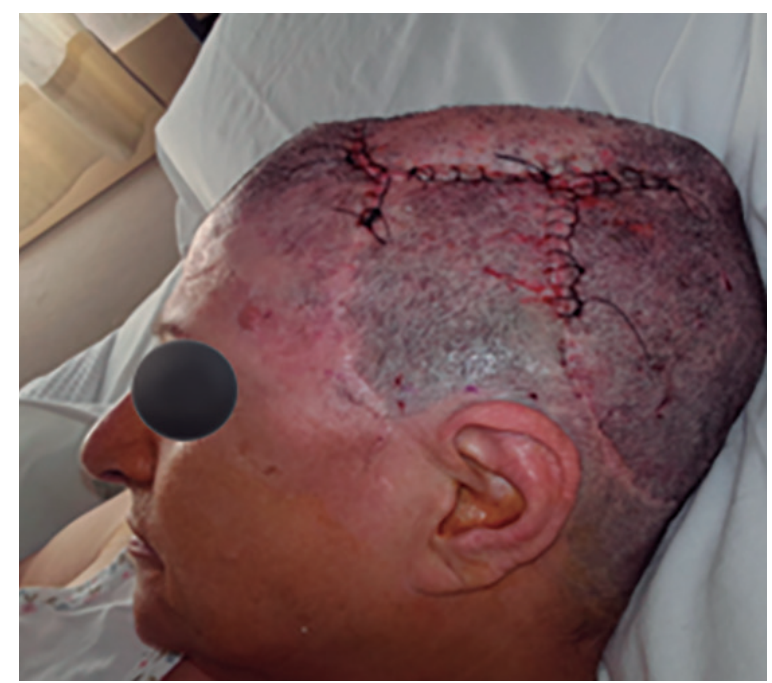

Figura 7. Posquirúrgico inmediato de la remoción de la placa craneal.

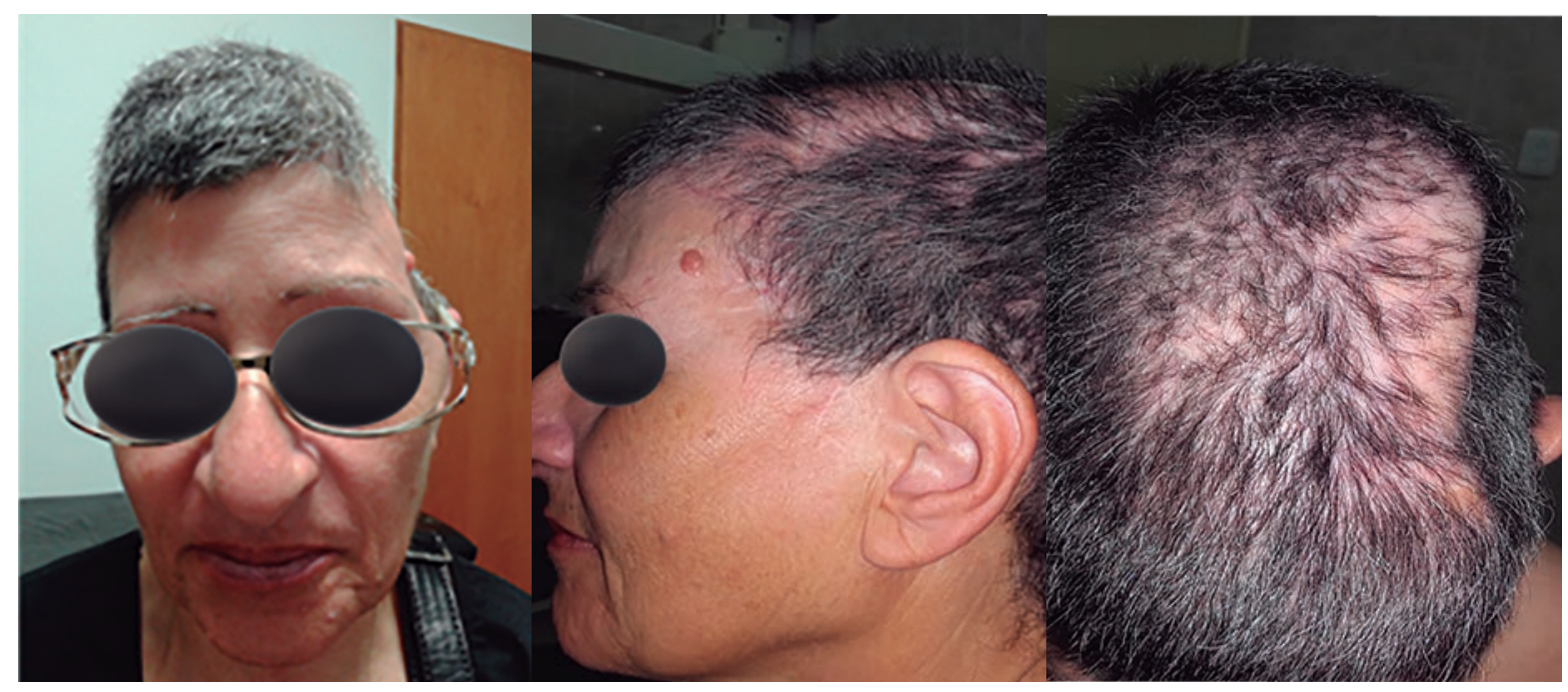

Figura 8. A 10 meses de la cirugía.

1. Infecciones (2,7-5\%). Estas pueden ser agudas o tardías: las agudas suelen ser poscirugía; las tardías, por llegada de gérmenes por vía hemática. Estas últimas son más frecuentes, y lo son más en aquellos pacientes a los que se les realizó la craneoplastia dentro del ler año del trauma, ya que la incidencia de infecciones disminuye si el tiempo entre el traumatismo y la craneoplastia es mayor o igual a un año.

2. También puede producirse un rechazo del injerto y pérdida del mismo, con necesidad de nuevas operaciones.

3. Hematomas epidurales.

4. Luxación del material de osteosíntesis por estar mal colocado, o exposición del mismo por algún nuevo trauma local, decúbito por apoyo en pacientes inmovilizados, infecciones, etc.

5. Dehiscencia de la herida por cierre con tejidos blandos de mala calidad, o expuestos a tensión.

6. Úlceras, entre las cuales la úlcera crónica de lar- ga duración es un reto terapéutico. Estas en general se inician en la línea de incisión y pueden exponer las estructuras óseas o la craneoplastia. Si el defecto que genera es pequeño, se pueden resolver por cierre primario o con algún colgajo local. Pero en general, las úlceras crónicas generan un adelgazamiento del cuero cabelludo en la zona, con inflamación crónica, mala vascularización local, lo cual dificulta la cicatrización y el cierre de la ulcera. Esto genera que el problema sea de difícil resolución.

\section{MATERIAL Y METODOS}

Paciente de 58 años (Figura 1) consultó en el año 2014, con el antecedente de haber sufrido un TEC con pérdida de conocimiento (PC) tres años antes (año 2011), secundario a un accidente de tránsito, en ese momento la paciente no presentaba ningún antecedente patológico concomitante. Se le había realizado una craneoplastia 8 meses posteriores al trauma inicial (junio 


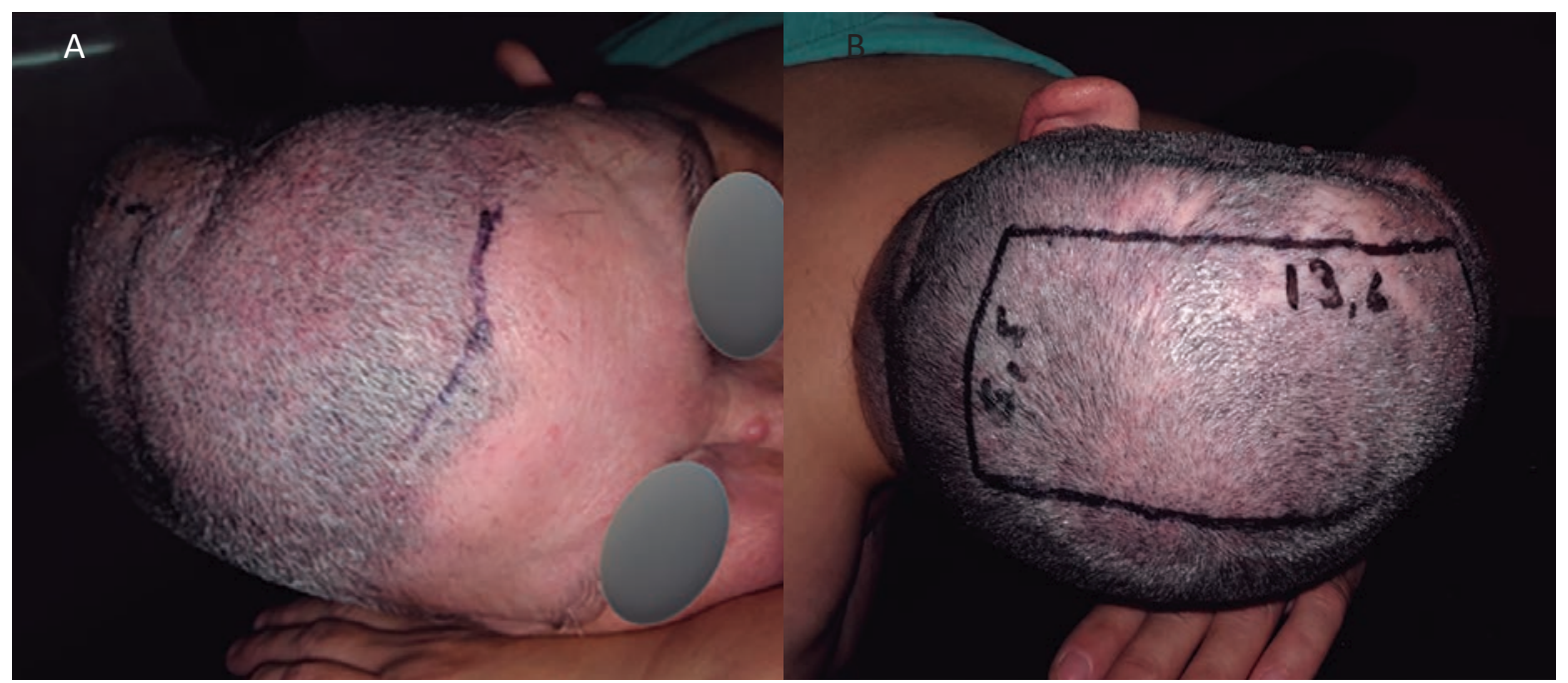

Figura 9. A) Marcación prequirúrgica de la región frontal a incidir para lograr el acceso del expansor. B) Marcación de la región donde quedaría colocado el expansor, y sus medidas.

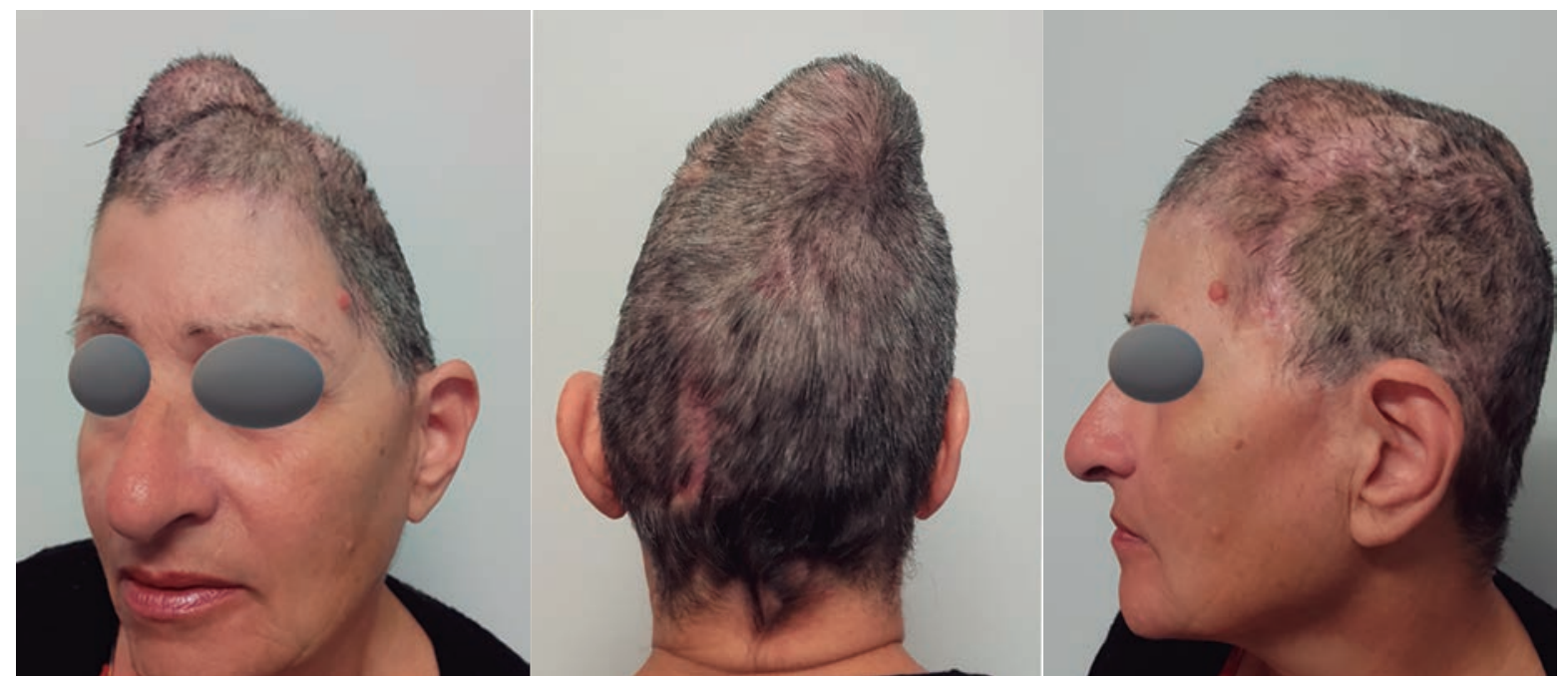

Figura 10. Expansión lograda del cuero cabelludo.

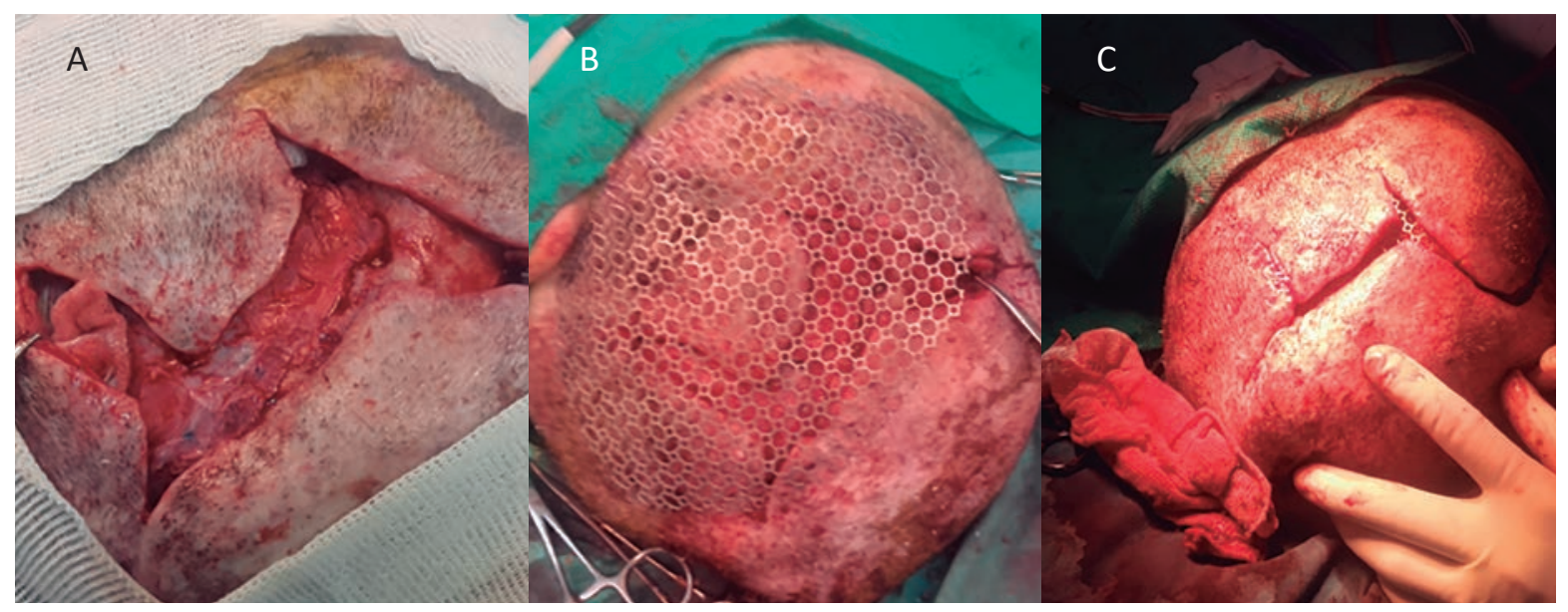

Figura 11. A) Zona a reparar (uego de la remoción del expansor. B) Placa de osteosíntesis sobre zona a reparar. C) Placa de osteosíntesis colocada y colgajos que la cubren sin tensión.

2012). A 10 meses de dicha cirugía (abril 2013), presentó una ulceración con exposición de la placa de cráneo, la cual fue resuelta con cierre por avance de colga- jos locales. A 6 meses de esta última intervención (octubre 2013), presentó una nueva ulceración con exposición del material de osteosíntesis, para la cual se le rea- 


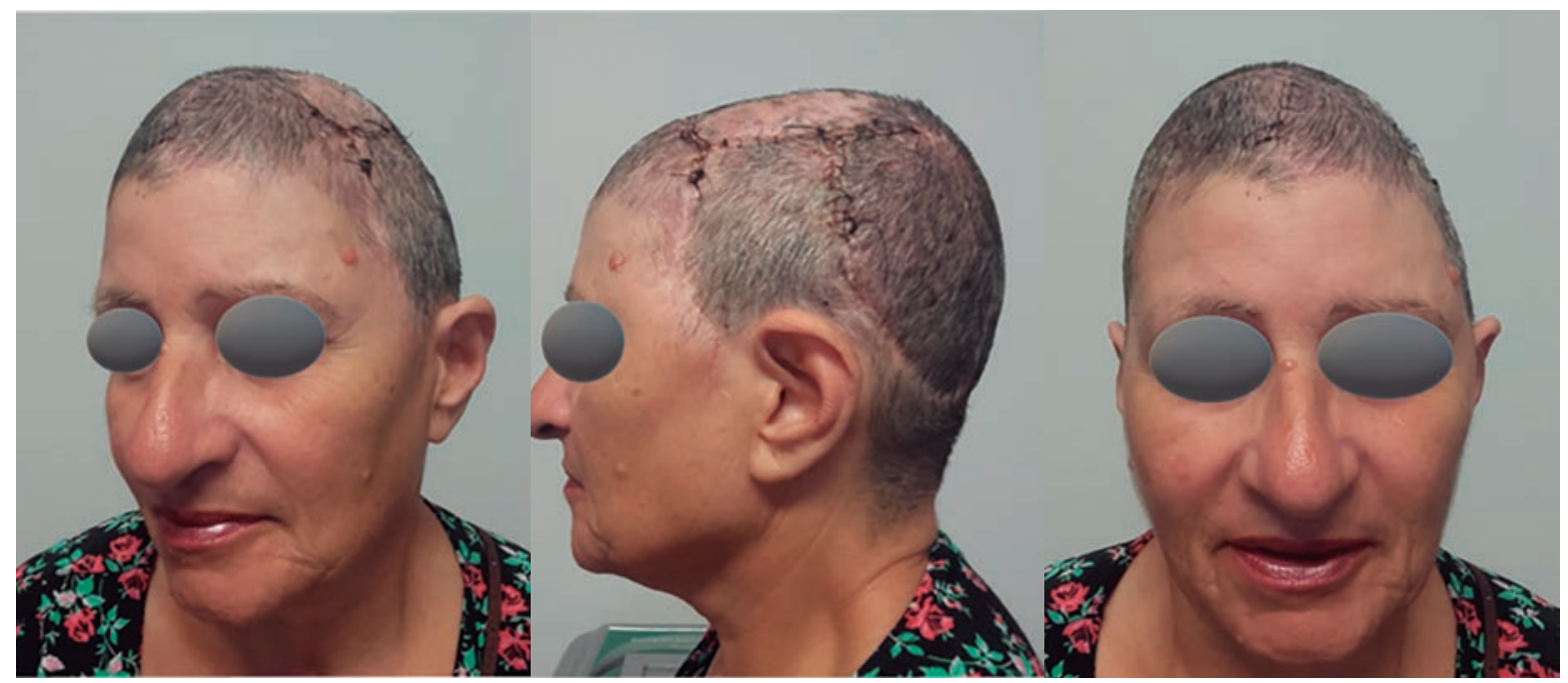

Figura 12. A 15 días de la cirugía reparadora.

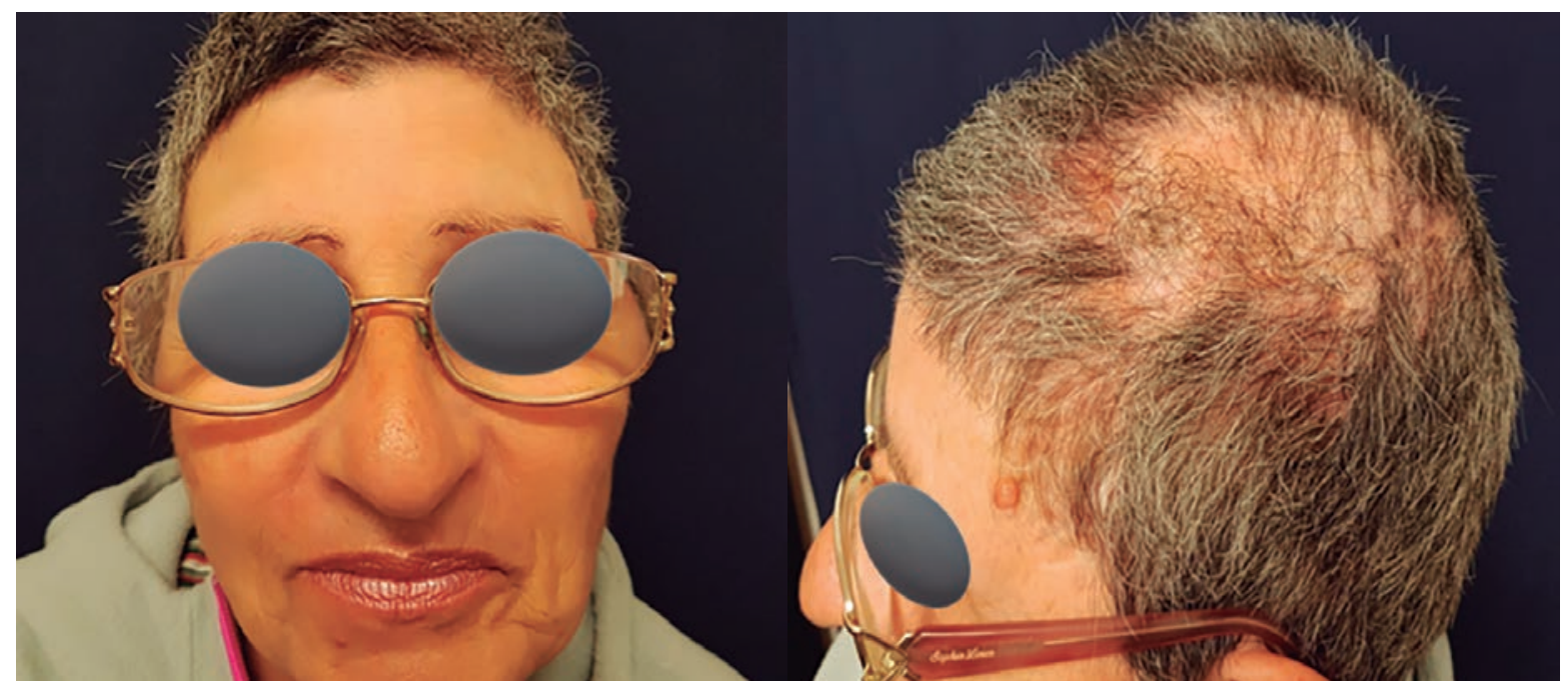

Figura 13. Resultados a dos años de la cirugía reparadora.

lizó un segundo avance de colgajos, sin remover el material de osteosíntesis subyacente; la paciente vuelve a presentar una nueva exposición de este material a los 5 meses del último cierre (marzo 2014).

$\mathrm{Al}$ momento de su primera consulta (Fotos 2 y 3 ), la paciente presentaba una exposición franca de la placa craneal en región parietal izquierda, y un adelgazamiento extremo del cuero cabelludo con pérdida de pilosidad y transparencia del material de osteosíntesis, en región frontoparietal izquierda (Figuras 3 y 4). Refería haber realizado varios tratamientos ATB previos, no presentaba signos de infección local, se realizaron cultivos con resultado polimicrobiano inespecífico (contaminación). A nivel neurológico presentaba una afasia de expresión, como única signo/sintomatología remanente al trauma.

Al examinar a la paciente en detalle, se identificaron múltiples cicatrices, remanentes de las cirugías reparadoras previas (Figura 4).

Luego se realizaron los estudios necesarios de tomografía computarizada con reconstrucción $3 \mathrm{D}$ para identificar el tamaño del material de osteosíntesis (Figura 5) y estimar la cantidad de sustancia ósea faltante (Figura 6).

Se consideró contaminado el material de osteosíntesis, como uno de los tantos motivos por el cual pudieron haber fracasado tantos intentos de reconstrucción. Se realizó el retiro del material de osteosíntesis craneal (octubre 2014) y, utilizando como vías de acceso las antiguas incisiones que presentaba la paciente, se realizó un cierre simple de las heridas, con remoción de las cicatrices de los bordes, presentando muy buena evolución (Figuras 7 y 8). Se realizaron cultivos del material de osteosíntesis, y estos resultaron polimicrobianos inespecíficos. El único tratamiento antibiótico que realizó la paciente en el posquirúrgico inmediato fue con amoxicilina + ác. clavulánico, 1 gramo cada 12 horas $\mathrm{x} 15$ días, sin presentar complicaciones posteriores.

\section{PLANTEOS DE RECONSTRUCCIÓN}

En conjunto con el Servicio de Neurocirugía, se planteó realizar la nueva craneoplastia con nuevo material 
de osteosíntesis, optando por el uso de una nueva placa de titanio premoldeada, con una curvatura menor a la que correspondía a la anatomía de la paciente, con el objetivo de restar tensión a los tejidos.

Para el cierre de partes blandas se planteó la posibilidad de realizar un colgajo libre microquirúrgico, pero no contamos con la suficiente experiencia en el equipo quirúrgico, y ante la negativa de la paciente de ser trasladada a otra ciudad para dicha intervención, se le propuso la expansión del cuero cabelludo y reconstrucción con colgajos del mismo.

\section{EXPANSIÓN TISULAR DE CUERO CABELLUDO}

Este tejido es ideal para ser expandido, pues debido a su grosor es progresivamente expansible y presenta una base firme (hueso craneal) que permite optimizar el uso del expansor. La expansión a su vez estimula la vascularizacion local. La zona a expandir debe tener un tejido de buena calidad, no comprometido por el proceso inflamatorio.

Al elegir un expansor, este debe ser del mayor volumen y mayor base posibles en relación con el tamaño de la zona a expandir. El expansor se debe colocar entre en pericráneo y la gálea, y en caso de ser necesario se pueden utilizar varias prótesis expansoras.

La vía de acceso para su colocación debe ser siempre a través de piel sana situada lejos de la zona a expandir, no debe afectar la irrigación del colgajo y en lo posible se realiza en forma radial o perpendicular a las tensiones más importantes de llenado del expansor.

La valvula protésica debe colocarse lejos del expansor y ser de fácil acceso, para facilitar el insuflado sin generar riesgos de lesionar el expansor.

El insuflado se inicia a las 2 a 3 semanas de colocada la prótesis, con solución fisiológica. El llenado debe ser lento, cada 3 a 10 días, y por un período de 1 a 3 meses. Pero lo más importante es tener en cuenta que el ritmo de insuflado y el volumen deben adaptarse a cada paciente, teniendo en cuenta signos como el dolor que esto genera, la tensión, el aspecto y el color que toma la piel en ese momento.

Existen posibles complicaciones ante la colocación de un expansor, y estas son: hematomas, desinflado de la prótesis, pérdida de la válvula, infección, exposición de la prótesis o válvula, que obliga al retiro precoz de la misma.

\section{RESULTADOS}

A 2 años de la cirugía de remoción de la placa craneal (noviembre 2016), la paciente fue reintervenida y se le colocó un único expansor rectangular de 13,6 x $5,5 \mathrm{~cm}$, paralelo al eje mayor de la pérdida de sustancia ósea (Figura 9).

El motivo por el cual se retrasó la reconstrucción por un lapso de 2 años, en lugar de realizarse al año de la primera intervención, fue la imposibilidad de obtener las prótesis expansoras necesarias, por motivos políticos ajenos a la paciente y el equipo quirúrgico.

El expansor se comenzó a insuflar a los 15 días de colocado, con insuflaciones seriadas cada 10 días, vertiendo un volumen de suero fisiológico de entre $10 \mathrm{ml}$ en un inicio y $5 \mathrm{ml}$ en las últimas sesiones. Esto fue realizado en un período de tres meses (Figura 10), al cabo del cual se comenzó a constatar pérdida de líquido desde la prótesis o la válvula, sin lograr mayor expansión de tejidos, por lo tanto, fueron suspendidas dichas expansiones y se programó la nueva craneoplastia.

Los colgajos más utilizados en la reconstrucción del cuero cabelludo son los de desplazamiento, y con menos frecuencia el de transposición; en su confección es posible seccionar la cápsula periprotésica, sin extirparla, para facilitar el avance del tejido. A los 3 meses del inicio del insuflado (febrero 2014), se reintervino a la paciente, se extrajo el expansor y, utilizando las mismas cicatrices de las cirugías previas, se tallaron colgajos de avance, se realizó un despegamiento de tejidos bien amplio y se logró cubrir la nueva prótesis sin tensión de las suturas, con previa remoción cicatrizal de los bordes de incisión (Figura11).

La paciente presentó buena tolerancia al procedimiento (Figura 12), sin exposición del material protésico a dos años de la cirugía reparadora, ni otras complicaciones de tipo infeccioso, fistuloso, secretantes y con buenos resultados estéticos (Figura 13).

\section{DISCUSIÓN}

Los resultados de este caso nos muestran el éxito que podemos lograr desde lo estético, pero sobre todo lo funcional, con un método sencillo como es la expansión tisular de un tejido tan noble como el cuero cabelludo, a pesar de haber sido intervenido quirúrgicamente en múltiples oportunidades.

Con este caso en particular no vivenciamos complicaciones, gracias a que la técnica fue delicada en todas las oportunidades en las que fue invadida la paciente, ya sea desde el manejo de los tejidos, como en la manipulación de los materiales y las técnicas de antisepsia empleadas.

Es muy importante destacar el cuidado que se tuvo en cuanto a los signos y síntomas que expresaba y presentaba la paciente en cada insuflado del expansor, ya que esto nos permitió adaptar la técnica a la paciente en particular, evitando, de este modo, complicaciones como la exposición precoz del expansor. Y si bien creemos que no llegamos al máximo de insuflación de la prótesis, debido a alguna falla del material, pudimos lograr la expansión necesaria para la cobertura que necesitábamos en el lapso de tiempo necesario. También el material de osteosíntesis se adaptó al caso, ya que se le dio una curvatura menor al lado contralateral del cráneo, para disminuir el riesgo de tensión del tejido. El cierre de las suturas se realizó en dos planos, resecando previamente los bor- 
des cicatrizales, para así brindar tejidos de mayor resistencia a las mismas. Creemos que el período de insuflación del expansor fue el momento clave para los buenos resultados que obtuvimos en este caso, así como la decisión de retirar la primera placa de craneoplastia, material que luego de estar expuesto tanto tiempo, se encontraba contaminado, y fue seguramente el origen de tantos fracasos anteriores.

\section{CONCLUSIÓN}

El trabajo multidisciplinario y adaptado a cada paciente en particular es la base fundamental de un buen tra- tamiento. El trabajo conjunto de equipos quirúrgicos multidisciplinarios es la piedra angular para la obtención de resultados óptimos en la reconstrucción de lesiones complejas.

\section{AGRADECIMIENTOS}

Agradezco al Dr. Mario Menon, Especialista Nurocirujano, por su participacion quirúrgica aportando todos sus conocimientos y experiencia, así como en la contención emocional de la paciente. Agradezco a la paciente y su familia por la confianza que depositaron en este equipo quirúrgico.

\section{BIBLIOGRAFÍA}

1. Manual de Cirugía Plástica SECPRE. Seccion I :Generalidades. Tema 4. Implantes. Técnicas de expansión tisular. Antonio Jesús García Hernández, Residente $3^{\circ}$ año. Hospital Universitario de Canarias (La Laguna, Tenerife); María Dolores Balsalobre Aznar, Residente $1^{\circ}$ año, Hospital Universitario de Canarias (La Laguna, Tenerife); Edmundo Rodríguez Rodríguez, Jefe de Servicio,. Hospital Universitario de Canarias (La Laguna, Tenerife); Javier A. Monsalve Díaz, Médico adjunto, Hospital Universitario de Canarias (La Laguna, Tenerife); Agustín Blanch Rubió, Jefe de Servicio de Cirugía Plástica de la Clínica M.A.Z. Sant Honorat de Barcelona. Pp. 53-71.

2. Encyclopedie Medico Chirurgicale de Cirugía Plástica y Reparadora. E-45-515. Vol.1. Cirugía de la pérdida de sustancia del cuero cabelIludo. Patrick Lafaurie. 2002, Editions Scientifiques et Medicales Elsevier SAS, París.

3. Encyclopedie Medico Chirurgicale de Cirugía Plástica y Reparadora. E-45-100. Vol.2. Técnicas de expansión cutánea. Guy Magalon, Jean Pierre Aubert, Jacques Bardot, Philippe Paulhe. Hospital de la Conception, Servicio de Cirugía Plástica y Reconstructiva. 2000, Editions Scientifiques et Medicales Elsevier SAS, París.

4. Sasaki Gh. Tissue expansion. Principles and practice (vol 2)"The CV Mosby Company. St.Louis, Baltimore, Philadelphia, Toronto. 1990.

5. Wang S, Long D, Shan S. Prevention and treatment of postoperative complications following skin soft tissue expansion. Chung Kuo Hsiu Fu Chung Chien Wai Ko Tsa Chih1998;12(1):33-4.
6. Argenta LC, Lacobucci JJ. Aplicaciones quirúrgicas de la expansión hística. Cirugía plástica, reconstructiva y estética. Vol. I: Editor Coiffman F. Ed. Ediciones cientificas y técnicas, Masson y Salvat Medicina, S.A., Barcelona, 1994. Pp. 666-77.

7. Chang CJ, Achauer BM, Vander Kam VM. Reconstruction of head and neck hemangiomas with tissue expansion in the pediatric population. Ann Plast Surg 1997;38(1):15-8.

8. Cherry GW, Austad ED, Pasky KA, Rohvich RJ. Increased survival and vascularity of random pattern skin flap elevated in controlled expanded skin. Plast. Reconstr Surg 1983;72:680-7.

9. Juri J, Juri C. Temporo-parieto-occipital flap for the treatment of baldness. Clin Plast Surg 1982;9:225.

10. Magalon G, Aubert JP, Bardot J, Paulhe PH. Técnicas de expansión cutánea. Encyclopedie Médico-Chirurgicale, Cirugía plástica, reparadora y estética. Vol I:Editor: Horay P. Ed. Scientifiques et Médicales Elsevier. Pp E-45-100-28.

11. Nordstróm Re. Expansión de tejidos. Revisión general. Cirugía Plástica, Reconstructiva y Estética. Vol 1; Editor Coiffman F. Ed. Ediciones científicas y técnicas, Masson y Salvat Medicina,S.A., Barcelona, 1994.Pp. 654-66.

12. Quetglas Marimón A. Expansores hísticos. Consideraciones generales. Cirugía Plástica, reconstructiva y estética.Vol I: Editor Coiffman F. Ed. Ediciones cientificas y técnicas, Masson y Salvat Medicina,S.A, Barcelona, 1994. Pp 645-53. 